\title{
UTILIZAÇÃO DE TÉCNICAS DE REALIDADE VIRTUAL E VISUALIZAÇÃO CIENTÍFICA PARA DESENVOLVIMENTO DE UM AMBIENTE DE TREINAMENTO TÉCNICO NA CONSTRUÇÃO CIVIL
}

\author{
F. P. Stange ${ }^{1}$, S. Scheer ${ }^{2}$
}

${ }^{1}$ Aluno do Programa de Pós-Graduação em Métodos Numéricos em Engenharia, Universidade Federal do Paraná (fpaulico1@gmail.com)

${ }^{2}$ DSc-Professor do Programa de Pós-Graduação em Métodos Numéricos em Engenharia, Universidade Federal do Paraná

\begin{abstract}
Atualmente a indústria da construção brasileira está passando por um processo de aquecimento econômico e se tornando um polo atrativo para os jovens. Eles estão se esforçando em aprender profissões relacionadas ao mercado da arquitetura, engenharia e construção (AEC). Estes jovens aprendizes pertencem a uma geração onde a informática, de forma ubíqua está presente em suas vidas, facilitando o acesso à informação $e$ ao conhecimento. O sujeito dessa geração não é mais um receptor passivo do conteúdo transmitido, mas um produtor do seu conhecimento através de midias interativas, que outrora eram de acesso exclusivo e hoje estão triviais. Mas o ensino brasileiro em AEC ainda está baseado num paradigma onde o conhecimento é centralizado exclusivamente na figura do educador que não explora os atuais recursos que essa geração está familiarizada. Isto ressalta a necessidade de mudar tal paradigma, abordando a computação na aprendizagem. Em paralelo a este contexto, a Realidade Virtual (RV) está mais acessível graças aos avanços na indústria da computação, tornando-se uma poderosa ferramenta para AEC. É neste contexto que o artigo foca seu objetivo: desenvolver uma ferramenta complementar de ensino adaptada a essa nova geração. Seguindo uma cronologia de pesquisas já realizadas pela instituição sobre $R V$, será apresento um estudo de um ambiente-protótipo de aprendizagem voltado à construção civil, baseado em alguns conceitos de serious games e metodologias de aprendizagem cognitiva. Optou-se em simular uma tarefa frequentemente encontrada nos canteiros de obra: a montagem de uma forma de um pilar de concreto armado. Com o uso de modeladores geométricos - como o Autodesk $3 d s$ Max - foi possível criar um canteiro de obra virtual para ser usado como cena. E exportá-lo num formato adequado para aplicar imersão e interatividade através de toolkits de visualização baseados em OpenGL tais como o Kitware VTK. O ambiente proposto originalmente é voltado a RV desktop (ou de mesa), mas será estudada a possibilidade em torná-lo uma $R V$ semi-imersiva. Espera-se que através da experiência da $R V$ o aprendiz consiga compreender a tarefa simulada de uma forma mais intuitiva e menos opressora que as antigas metodologias abordadas em sala de aula. Além de estimular os educadores em buscar pedagogias mais motivadoras e inovadoras.
\end{abstract}

Keywords: Realidade Virtual, Aprendizagem, Construção. 


\section{INTRODUÇÃO}

A indústria da construção brasileira está passando por um processo de aquecimento econômico e se tornando um polo atrativo para os jovens, que estão se esforçando em aprender profissões relacionadas ao mercado da arquitetura, engenharia e construção (AEC). Estes jovens aprendizes pertencem a uma geração onde a informática está presente em suas vidas, facilitando o acesso à informação e ao conhecimento. O sujeito dessa geração não é mais um receptor passivo do conteúdo transmitido, mas um produtor do seu conhecimento através de mídias interativas, que outrora eram de acesso exclusivo e hoje estão se tornando triviais. Os alunos estão mais preparados para serem influenciados por novas tecnologias devido a sua presença no cotidiano deles [8], [26].

Mas o ensino brasileiro em AEC continua baseado num paradigma onde o conhecimento é centralizado exclusivamente na figura do educador que geralmente não explora os atuais recursos que essa geração está familiarizada. Ainda, os campos da engenharia não são os mais os mesmos. Aprendizado interativo, pensamento critico, criatividade em resolução de problemas são as bases para educação em engenharia, mas ainda continua passiva. Nem todas estas habilidades são adquiridas na universidade, mas quando o aprendiz já está inserido no mercado de trabalho. Existe a necessidade de mudança desse paradigma, sendo que uma abordagem está na computação relacionada à aprendizagem. O processo educativo deve se atualizar para combater a discrepância entre ensinamento e aprendizagem, devendo estar atento às diferenças entre interatividade homem/homem e homem/máquina e na comunicação entre professor e aluno através do bom uso da tecnologia, buscando maior qualidade ao próprio profissional, a instituição e ao curso [8], [13], [26].

Paralelo a este contexto, a Realidade Virtual (RV) está mais acessível graças aos avanços na indústria da computação e possibilitando seu uso no ensino voltado a AEC. A RV oferece tudo que os outros programas gráficos oferecem, porém com mais motivação através da busca do estímulo ao aprendiz, provendo exame mais próximo do objeto, participação de deficientes físicos, maior liberdade no tempo do aprendiz em contrapartida de horas fixas com aulas, encoraja a participação ativa ao invés da passiva. Principalmente quando o modo tradicional oferece perigo, é prejudicial ao ambiente, custo, não existe possibilidade de se experimentar. A RV permite uma experiência de aprendizado multiperceptiva, e não vai solucionar todos os problemas de educação, mas é possível mostrar ao professor que a RV é uma opção para a sala de aula [25], [26], [27].

O objetivo do uso de RV é aumentar a performance humana [22]. E esta performance se relaciona com o processo cognitivo humano. Cognição é o ato ou processo de conhecer envolvendo atenção, percepção, memória, raciocínio, juízo, imaginação, pensamento e linguagem. É um processo complexo que é predicado da interação senso-motor dos indivíduos e seus sistemas neurológicos. Isto é possível desde que a RV seja usada junto com um instrutor/tutor/professor em guiar os aprendizes tal como um dugeon master em um jogo de RPG guia os players. Atualmente se busca no conceito de serious games simular, treinar e educar com o uso de consoles e pc transferindo experiencias positivas na construção do conhecimento. 
A perspectiva do aprendizado construtivista afirma que os aprendizes provavelmente criam novas ideias quando estão comprometidos ativamente ao criar seus próprios projetos que serão compartilhados com outros, ou seja, o conhecimento pode ser construído pelo próprio aprendiz. A teoria construtivista levanta suposições pertinentes a RV: a construção do próprio entendimento através da interatividade com o ambiente virtual, a construção do conhecimento colaborativa com o uso de um avatar, por exemplo, que não permite o aprendiz ser deixado sozinho na construção do conhecimento. Então a RV é uma poderosa ferramenta para aprendizado construtivista. É um ambiente experimental e intuitivo, promove interatividade única, dá suporte a debates por ser um aprendizado tanto individual como coletivo. Experimenta tentativas de forma segura e experimenta consequências e então escolhe o conhecimento [16], [22], [25], [26].

Este trabalho estuda o desenvolvimento de um ambiente protótipo como ferramenta complementar de ensino adaptado a essa nova geração. $\mathrm{O}$ ambiente protótipo é voltado a $\mathrm{RV}$ desktop (ou de mesa) onde um usuário por vez pode experimentar um treinamento virtual de uma atividade típica da construção. A escolha deste tipo de RV está no fato do custo elevado em construir um ambiente virtual imersivo. Porém este ambiente protótipo pode ser adaptado à RV imersivas. Espera-se que este ambiente protótipo possa ser usado como uma forma de aprendizagem mais intuitiva e menos opressora que as antigas metodologias abordadas em sala de aula, além de estimular os educadores em buscar pedagogias mais motivadoras e inovadoras. No capítulo 2 e capítulo 3 são apresentados os conceitos de Visualização Científica e Realidade Virtual, respectivamente. No capítulo 4 será explicado o ambiente protótipo para aprendizado, o treinamento simulado e sua implementação. No capítulo 5 apresenta-se a conclusão.

\section{COMPUTAÇÃO GRÁFICA E VISUALIZAÇÃO CIENTÍFICA}

A partir do século $\mathrm{X}$ os cientistas usavam gráficos e imagens como apoio ao estudo da ciência. Descobertas nas áreas do conhecimento científico foram bem compreendidas graças à visualização. Atualmente, a visualização e a computação visual são ferramentas valiosas no processo de interpretação e comunicação da informação, inclusive está promovendo uma mudança no paradigma corrente de comunicação baseado em palavras e simbologia através de imagens tridimensionais, interfaces gráficas e animações [7].

A computação gráfica estuda os processos computacionais envolvendo modelos geométricos e imagens digitais. É representada por uma taxonomia onde modelos geométricos podem ser transformados em imagens digitais por processos de síntese de imagens. $\mathrm{O}$ processo inverso é chamado de análise de imagem. A modelagem geométrica e processamento de imagem estão relacionados à criação e manipulação de dados. Se por um lado temos a modelagem geométrica com o foco de apresentar imagens, a visão computacional faz o caminho inverso ao gerar um modelo geométrico ao se visualizar uma imagem [31].

A visualização científica (VC) é uma área da computação que pesquisa técnicas de processamento de imagens e computação gráfica para tratar visualmente dados científicos 
procedentes de medições físicas e simulações numéricas. Estuda ferramentas de visualização para auxiliar o desenvolvimento de sistemas computacionais e técnicas para visualizar informações sem natureza gráfica [24]. É uma ferramenta para entender a estrutura global do campo das variáveis e suas interconexões, analisando qualitativamente a natureza das soluções numéricas através da computação gráfica [21].

\subsection{Processo de visualização por computação}

A visualização por computação explora os dados através de um modelo empírico, a transformação destes em objetos gráficos por um mecanismo de visualização, e a exposição dos objetos gráficos através de dispositivos [24]. Os dados são obtidos por experimentos ou simulações numéricas de modo discreto. Algoritmos de interpolação são usados na busca de valores desconhecidos do domínio evitando introduzir erros significativos. A transformação usa algoritmos de visualização (filtros e mapeadores) para modelagem geométrica e/ou processamento de imagem digital, resultando num formato conveniente de apresentação dos dados do domínio [1]. Estes são representados em sistemas de visualização que dependem dos dispositivos gráficos e técnicas de representação que estão disponíveis em Application Programming Interfaces e toolkits que facilitam as representações por computação gráfica, a manipulação da visualização por rotinas prontas e ajudam no desempenho e economia em códigos computacionais de interface com o hardware gráfico [7].

Um paradigma de processo de visualização adotado em diversos sistemas é o modelo de fluxo de dados (daflow) [6]. Um conjunto de módulos gerencia o fluxo da entrada e saída de dados através de filtro, mapeador e renderizador. O filtro extrai as informações relevantes dos dados nativos através de operações como interpolação e suavização. $O$ mapeamento transforma as saídas dos filtros em geometria por operações para criar volume, cor, contorno. A renderização transforma a saída do mapeamento em imagem a ser visualizada num dispositivo gráfico. A figura 1 apresenta o pipeline do modelo de fluxo de dados.

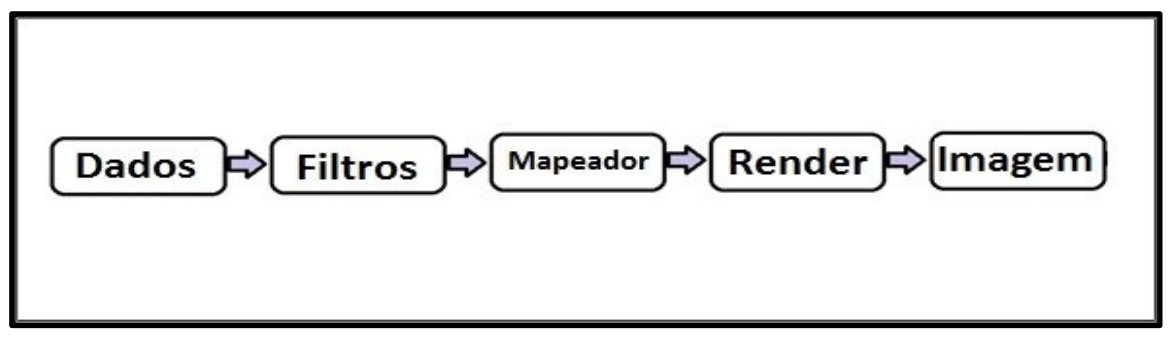

Figura 1. Modelo de fluxo de dados. Adaptado de [6].

\subsection{Componentes de visualização por computação}

A modelagem geométrica é um conjunto de componentes com geometria e aparência bem definidas, existindo uma conectividade entre estes componentes como os encontrados em estruturas arquitetônicas e de engenharia [12]. Os objetos gráficos são modelados conforme a 
geometria projetiva que engloba a geometria Euclidiana, as operações de transformações lineares e a projeções visuais ortogonais e perspectivas. As formas geométricas destes objetos gráficos são descritos por funções matemáticas paramétricas, implícitas ou explícitas. A representação do modelo incide na descrição topológica e geométrica. A topologia relaciona os vértices, arestas e faces, enquanto a geometria diz a posição no espaço das entidades do modelo geométrico. São representados através de primitivas geométricas como o ponto e a reta [2], [31].

Uma classificação para a representação de modelagem é apresentada em Mäntylä [20]: modelo de decomposição que representa formas geométricas através da "colagem" entre entidades geométricas; o modelo construtivo conecta as entidades geométricas por operações mais sofisticadas como união, subtração e intersecção (operações booleanas); o modelo de contorno (B-rep, Boundary representation) que molda o contorno do modelo distinguindo exterior do interior por uma superfície orientada e dividida conveniente por polígonos. A combinação dos modelos de representação já citados é dita de representação híbrida.

A cor tem um papel fundamental, pois ressalta aspectos da informação da imagem tornando o processo de comunicação mais eficiente. Cor é a sensação provocada pela radiação eletromagnética através do sentido da visão humana. Isto envolve três tipos básicos de cores visíveis pelo homem: vermelho, verde e azul. O grau da qualidade da cor depende da quantidade de sensores e emissores do dispositivo gráfico e ainda, como a função de distribuição espectral foi reconstruída. O sistema mais usual de cor é modelo RGB (red, green, blue) que formam uma base para colorir um pixel [1], [2], [7], [31].

A textura é a variação da cor na superfície do objeto em função da rugosidade, transparência e posição do observador. O objetivo é evocar uma sensação similar à superfície real do objeto físico modelado, melhorando a aparência. Em termos computacionais a textura é obtida por mapeamento de uma imagem ou procedural. O mapeamento de imagem relaciona o espaço paramétrico da imagem ao espaço preenchido pelo objeto gráfíco. Os mapas procedurais são um conjunto fixo de pixels coloridos para simular textura sem o uso de imagem [1], [2], [7], [31].

Câmera virtual ou sintética é a forma computacional de visualizar objetos. Deve-se informar: posição no mundo virtual, o ponto focal que orienta a direção projeção, o vetor que indica o lado de cima (view-up), os planos que delimitam a profundidade da cena (clipping planes) e tipo de projeção (ortogonal ou perspectiva) [1], [2], [7].

Cena virtual ou apenas cena é a descrição gráfica e computacional de um mudo virtual para representar aspectos relevantes para a visualização de objetos pertinentes a este mundo. Fazem parte da cena: objetos gráficos, as fontes de luz, a câmera virtual, as relações e vínculos entre os objetos e configuração [31].

Rendering é o processo de criação de uma imagem em um dispositivo de visualização conforme uma descrição computacional [24]. É o processo de sintetizar uma cena gerada por computador até obter uma aparência conforme as seguintes etapas: criação da aparência tridimensional através de projeções ortogonais e perspectivas; eliminação das faces escondidas devido à posição entre objeto e observador (culling back-faces); recorte de objetos da cena cuja visualização não está no campo de visão (clipping); converter a representação tridimensional em pixels (rasterização); esconder as faces por causa da obstrução ocasionada 
pela posição relativa entre os objetos; colorir cada pixel em função da simulação da iluminação, brilho, transparência e reflexão e sombra [1], [2], [7], [24].

\section{REALIDADE VIRTUAL}

As evoluções das pesquisas resultam em dados mais complexos e, por consequência, existe a dificuldade em buscar padrões assim como informações pertinentes. Para ressaltar tais informações as técnicas de visualização científica exploram o sentido mais aguçado do ser humano, a visão. Quando se usa a realidade virtual, ela proporciona uma experiência maior, pois possibilita explorar os demais sentidos humanos através de interfaces inovadoras [23]. VC serve basicamente para lidar com grandes conjuntos de dados para serem visualizados de forma que se achem padrões, tendências com o uso da computação. Ao unir RV com VC tenta-se descobrir uma medida psicológica objetiva, sensível, valida e confiável. Mesmo estando em campos diferentes, VC ainda possui restrições como latência, frame rate e outros que podem ser vencidos pelas ferramentas de RC [30].

O termo realidade virtual (RV) começou ser usado pelo norte-americano Jaron Lanier para distinguir simulações computacionais tradicionais de simulações envolvendo múltiplos usuários em um ambiente compartilhado [23]. É uma simulação do espaço-tempo formada pelos seguintes elementos: universo ou cena, sensores de resposta aos comandos enviados à cena, gerenciador para controle das regras do universo e ações e respostas das entidades [26]. Não se deve confundir RV com CAD (computer aided design), animação e multimídia. Comparada a estes sistemas, a RV oferece uma sensação maior de interface homem-máquina além de formas mais intuitivas para manipular o comportamento de entidades de uma cena [23].

\subsection{Imersão, interatividade e envolvimento}

Imersão é a sensação de estar "dentro" de uma cena de RV. O grau de imersão do usuário de RV está relacionado com a sua percepção em relação ao espaço físico que o cerca. Ou seja, quanto maior a imersão proporcionada pela RV ao usuário, menor será sua percepção do mundo real, ou não distinguir mundo virtual do real quando ambos estão misturados.

A capacidade do computador em detectar movimentos do usuário e modificar/atualizar a cena de RV em resposta a essas ações está atribuída à definição de interatividade (ver [4]).

O envolvimento está ligado ao grau da motivação do usuário ao interagir, ativa ou passivamente, com um sistema de RV [23].

\subsection{Percepção}

Aproximadamente $70 \%$ dos receptores de estímulos ligados aos cinco sentidos estão concentrados no olho humano [14]. Assim, é natural esperar que pesquisas e projetos de tecnologias em RV enfoquem seus esforços nas interfaces de visualização. 
A percepção visual é a capacidade de distinguir forma, cor, textura, posição alvos dentro do seu campo de visão humana. São três as categorias de estímulos visuais: informações monoculares, informações óculo-motoras e informações estereoscópicas. Informações monoculares estão relacionadas à perspectiva linear, oclusão, textura, reflexão da luz, sombra e conhecimento prévio do alvo. Informações óculo-motoras estão relacionadas com o ajuste do foco e a distância do alvo. Informações estereoscópicas estão relacionadas com a profundidade da imagem pela paralaxe, ou seja, distância entre imagens esquerda e direita [12].

Mesmo que a percepção visual represente a maior porcentagem dentre os sentidos, a percepção tátil e auditiva também deve ser explorada, tais como o uso de luvas com sensores flexíveis para simular o tato [3], [34]. Myron Krueger [19] apresentou um dispositivo para cegos denominado KnowWhere ${ }^{\mathrm{TM}}$ que está voltado a exploração da audição.

\subsection{Navegação}

A navegação é o resultado da combinação entre o movimento do ponto de vista (câmera virtual) com o processo cognitivo para se traçar e/ou escolher um caminho [4]. É a forma mais usual de interatividade entre usuário e sistema de RV. A figura 2 apresenta uma taxonomia de navegação, e diz respeito à exploração da cena de RV seja ela passiva ou préprogramada, exploratória (sem alteração na cena) ou interativa (com alteração na cena).

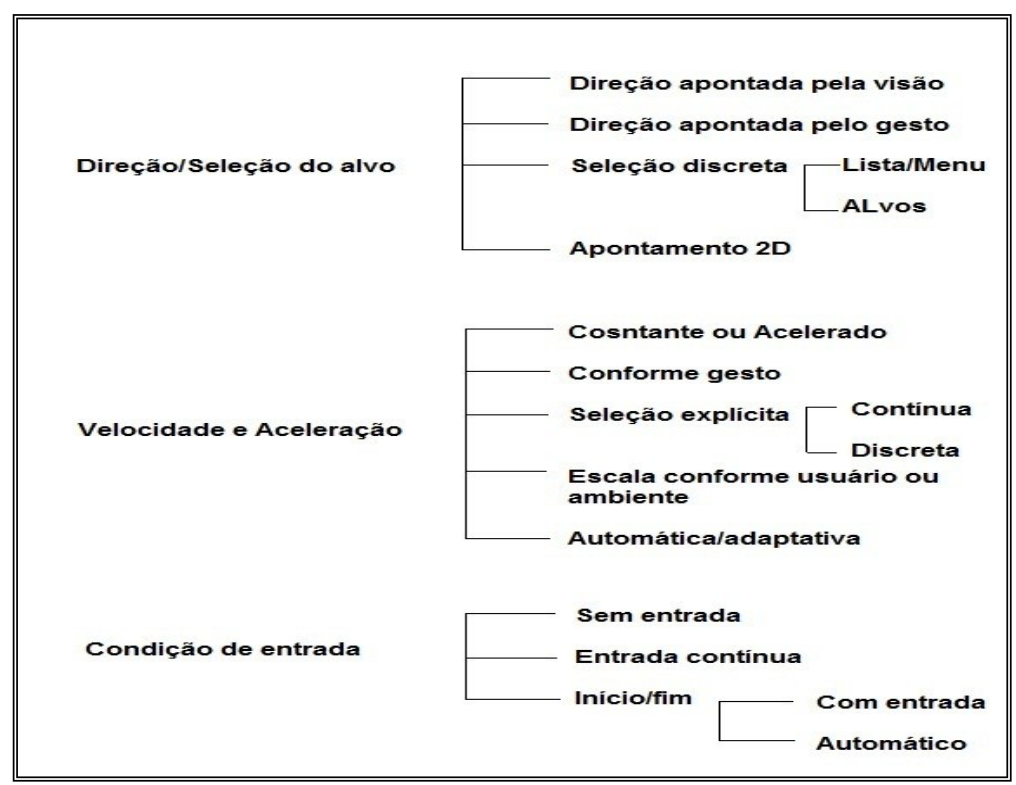

Figura 2. Taxonomia de navegação em RV. Adaptado de [4].

A direção/seleção do alvo se refere ao método de controle e movimentação contínua ou não do ponto de vista da câmera. A velocidade e aceleração estão relacionadas à taxa de movimento ao longo da cena. A condição de entrada diz respeito ao tipo de controle conforme as especificações do sistema. Alguns exemplos navegação: fly que permite ao usuário voar na 
cena; point-and-fly no qual o usuário aponta para algum local da cena através de um dispositivo para navegar; eyeball-in-hand é a navegação na cena por um dispositivo de interação com 06 (seis) graus de liberdade; no scene-in-hand o ponto de vista do usuário é fixo e a cena é se movimenta [23], e ainda tem-se a walk, que simula uma pessoa caminhando na cena.

\subsection{Classificação}

Existem diversas formas de classificar a realidade virtual. Mesmo havendo particularidades nestas classificações, elas acabam tendo o mesmo foco: a questão da imersão, ou seja, o uso de dispositivos que escondem o mundo real do usuário.

A RV pode ser classificada em dez tipos: 1) Realidade Virtual Imersiva em Primeira Pessoa permite ao usuário uma sensação de estar na cena ao se estimular a percepção visual, auditiva, tato e olfato por uso de dispositivos de interface sofisticados; 2) Realidade Aumentada é o aumento da percepção do usuário por meio de dispositivos de visualização para misturar objetos virtuais ao mundo real; 3) Through window, ou desktop, ou world on window é uma RV cuja visualização, navegação e interatividade podem ser realizadas por equipamentos menos sofisticados, convencionais e de baixo custo como monitores, mouse, teclado, entre outros; 4) Realidade Projetada/Artificial, ou mirror world proporciona a criação de um personagem ou ator virtual em terceira pessoa (também conhecido por avatar); 5)Waldo word é o termo usado para captura de movimentos e/ou expressões faciais de um usuário e reproduzidos (em tempo real) por uma marionete virtual; 6) Câmara é uma RV cujo envolvimento é alcançado através de uma sala real que permite movimentação com maior liberdade a um ou mais usuários e são usados diversos computadores para geração e monitoramento da RV que é projetada nas paredes da câmara como o sistema CAVE; 7) Cab simulator, ou realidade virtual de simulação são cabines físicas onde os usuários ficam envolvidos na simulação sendo uma extensão da RV Câmara; 8) O ciberespaço de William Gibson em seu livro Neuromancer, e definido como um mundo dominado por redes de computadores e dados para simular uma realidade artificial; 9) Visiodome é um ambiente físico de RV imersiva projetado pela Elumes Corporation, e consiste em uma estrutura hemisférica que proporciona imersão de $360^{\circ}$ num plano paralelo ao piso e imersão de $180^{\circ}$ num plano perpendicular ao piso; 10) Experience learning system que procura simular emoções tais como pânico, tensão, medo e ansiedade, com base nas ações e decisões tomadas pelo usuário.

Completando a classificação cita-se: Ambientes Virtuais Colaborativos (AVC), proporcionam interação em tempo real de multiusuários com acesso simultâneo a RV, sendo que os usuários não precisam estar no mesmo espaço físico, mas conectados em uma rede ligada a RV; Tele Existência, ou Tele Presença, é o estímulo que o sistema de RV provoca no usuário de estar num local sem sua presença física [9], [10], [11], [14], [19], [22]. 


\section{AMBIENTE PROTÓTIPO DE TREINAMENTO}

O dia-a-dia em um ambiente de construção civil engloba uma gama de tarefas que estão relacionadas com o propósito da obra de engenharia. Ainda, a questão da abordagem de qual técnica construtiva será mais eficiente e/ou resultará num produto com maior qualidade depende do perfil da obra assim como da equipe responsável sobre o empreendimento. Mesmo quando se busca padronizar as atividades de construção conforme normas e processos construtivos conceituados cientificamente, dificilmente há uma única abordagem para uma mesma tarefa. Até mesmo a escolha da metodologia de execução das atividades em uma obra de construção civil depende de fatores que podem ultrapassam os conhecimentos adquiridos durante a formação acadêmica do engenheiro.

Para este trabalho foi desenvolvido um ambiente protótipo para simular a atividade de montagem de uma fôrma para moldar um pilar de concreto armado. Mesmo sendo uma tarefa muito comum na construção civil brasileira e independente do tamanho da obra, existem mais de um modo para abordar esta atividade. Em parte por causa das diversas técnicas construtivas e em parte por causa das escolhas adotadas pelos engenheiros e encarregados em executar a obra quando existe a possibilidade de combinar estas técnicas. Foram encontrados pelo menos seis metodologias de execução de fôrmas para moldar peças de concreto armado conforme as recomendações da Associação Brasileira de Cimento Portland (ABCP) [15]. E ainda, os cursos de engenharia civil no Brasil não contemplam todas as variações das técnicas existentes de construção. É por isso que este ambiente protótipo de aprendizagem serve como complemento ao instrutor e cabe a este sujeito averiguar quando é possível adotar ou modificar o treinamento conforme seu plano de ensino. $\mathrm{O}$ ambiente protótipo de treinamento foi concebido a princípio para ser uma realidade virtual world on window ou desktop para um usuário por vez.

Para a implementação do ambiente protótipo foi usado o pacote de visualização (toolkit) VTK versão 5.4 para criar a interatividade na cena do ambiente protótipo. O VTK é um toolkit orientado a objetos que vem se destacando no campo da visualização científica. Softwares para modelagem geométrica como Autodesk 3ds Max, Google Sketch-up permitem desenvolver com certa facilidade uma cena virtual além de oferecer ferramentas para exportar a malha geométrica dos objetos da cena num formato que seja compatível com o VTK; um notebook equipado com um processador Intel Core i7-2630 $2 \mathrm{GHz}$, memória RAM de 6GB, sistema operacional Microsoft Windows 764 bits, uma placa de vídeo NVIDIA GeForce GT 540M; um compilador Microsoft Visual C++ 2008 Express Edition que serviu como IDE para a programação das funcionalidades do ambiente protótipo.

\subsection{Descrição da cena virtual e da tarefa a ser executada}

A cena virtual modelada consiste em um canteiro de obras situado num ambiente urbano virtual, cercado por edificações e ruas. O canteiro de obras é delimitado por tapumes e possui um alojamento para funcionários e um abrigo, que serve como almoxarifado com ferramentas, materiais construtivos e as peças da fôrma já produzidas. No canteiro de obras existe uma estrutura de concreto armado que se encontra com a fundação, blocos e vigas de 
baldrames já executadas. Existem oito pilares de concreto armado, sendo que sete destes pilares já estão concretados. A tarefa a ser simulada será executar o processo de montagem de uma fôrma para moldar o pilar a ser concretado. As peças da fôrma se encontram no canteiro de obras.

O ambiente protótipo começa com uma tela inicial de apresentação e demais telas surgem informando ao usuário sobre as características da atividade através de ilustrações e texto informativo (figura 3 e figura 4). Então abre-se a tela para cena. No canto superior direito da janela de visualização da cena existe uma legenda que informa ao aprendiz o que ele deve fazer durante a atividade, indicando qual a peça na sequência e sua localização no canteiro de obras virtual. Durante a simulação, usa-se o mouse para escolher uma peça relacionada à sequência de montagem. Existe outra peça idêntica na cena, na cor magenta, que indica ao usuário a posição que a peça escolhida deve ser locada. Sucede-se até o término da simulação da atividade de montagem da fôrma.

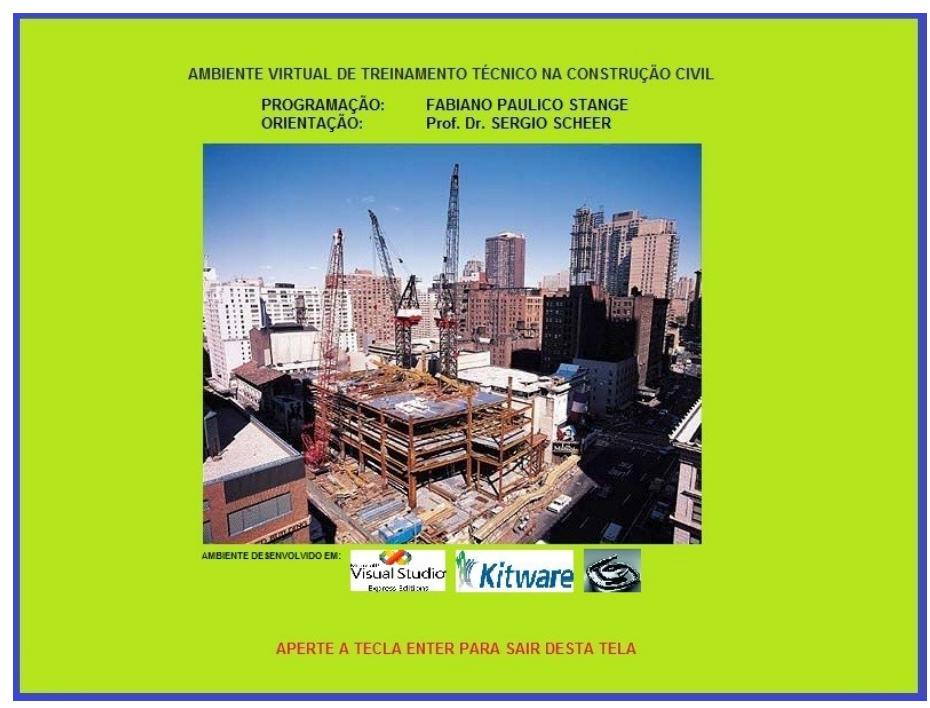

Figura 3. Tela Inicial.

A navegação na cena fornecida ao usuário pelo ambiente protótipo ocorre através de uma câmera virtual implementada pelas rotinas do VTK. Durante a sincronização entre os objetos modelados e as rotinas de interface e interatividade foram testados os recursos oferecidos pelo VTK na manipulação da câmera virtual. Optou-se por aquele que simula uma navegação fly, pois oferece ao aprendiz maior liberdade tanto para explorar a cena como para executar a atividade ao facilitar a movimentação e locação das peças através das possíveis posições que o usuário pode aproveitar para o seu campo de visão como mostra a figura 5. Apesar desta navegação não representar como um sujeito executa a montagem da fôrma no mundo real, a ideia é transmitir conhecimento aos aprendizes sobre as técnicas construtivas usando RV como suporte ao instrutor, através do estímulo que a RV provê ao aprendiz como interface intuitiva ao aprendizado, não supondo que o usuário é especialista. Cabe ao instrutor dar suporte sobre como usar o sistema, pois se considera que o aprendiz não é especialista no ambiente protótipo virtual. 


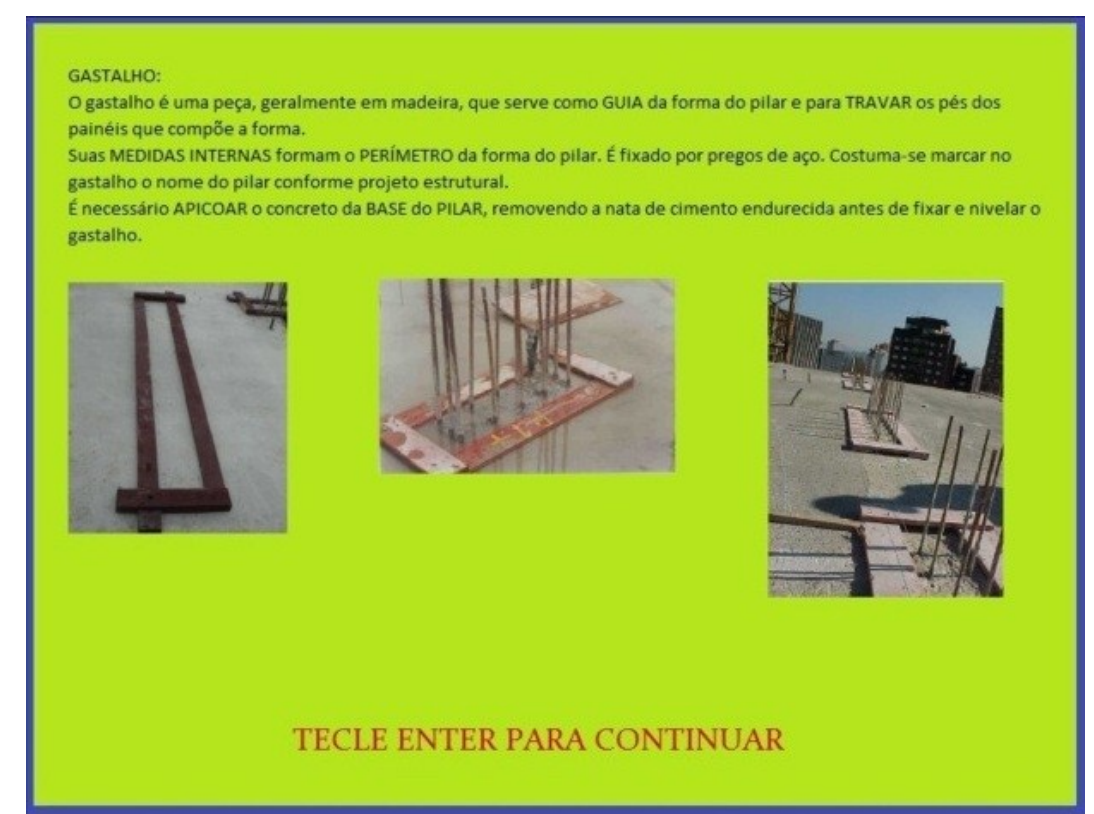

Figura 4. Tela com informações sobre a atividade.

Como já mencionado anteriormente existem pelo menos seis técnicas para se executar uma fôrma de madeira para moldar um pilar de concreto: sistema tradicional, sistema Ueno, sistema FORMAPRÉ, sistema FORMAPRONTA, sistema PRÁTIKA e o sistema GETHAL. Estas técnicas se baseiam no sistema tradicional descrito no boletim técnico n. 50 de 1943 da ABCP e servindo de base para as demais técnicas [15]. As recomendações deste sistema são:

a) Execução das fôrmas conforme as dimensões das peças de concreto descritas no projeto estrutural;

b) A fôrma deve possuir rigidez suficiente para não ocasionar defeitos na moldagem das peças de concreto;

c) Evitar perda de cimento durante o molde da peça com concreto (concretagem) observando a estanqueidade da fôrma;

d) As fôrmas devem estar projetadas para permitir a retirada das partes da mesma com facilidade, devem ser executadas permitindo o maior número de reutilizações.

A metodologia adotada para simular o procedimento construtivo foi baseada no sistema GETHAL [15] e [32], no qual são utilizadas chapas de madeira compensada com espessuras de $18 \mathrm{~mm}$ para painéis e retos e $12 \mathrm{~mm}$ para painéis curvos; escoras metálicas e fôrmas das lajes e vigas conforme sistema GETHAL de escoramento. Para os painéis de pilares existem alguns modos de execução: a) painéis enrijecidos por sarrafos duplos de 1"x4" ou caibros de 3"x3"e travados por barras de ancoragem (tirantes); b) gravatas moduladas por sarrafos e encaixes metálicos; c) placas com peças metálicas e revestida com madeira compensada conforme figura 6. Foi adotado para a simulação o modo de execução descrito em (a). 


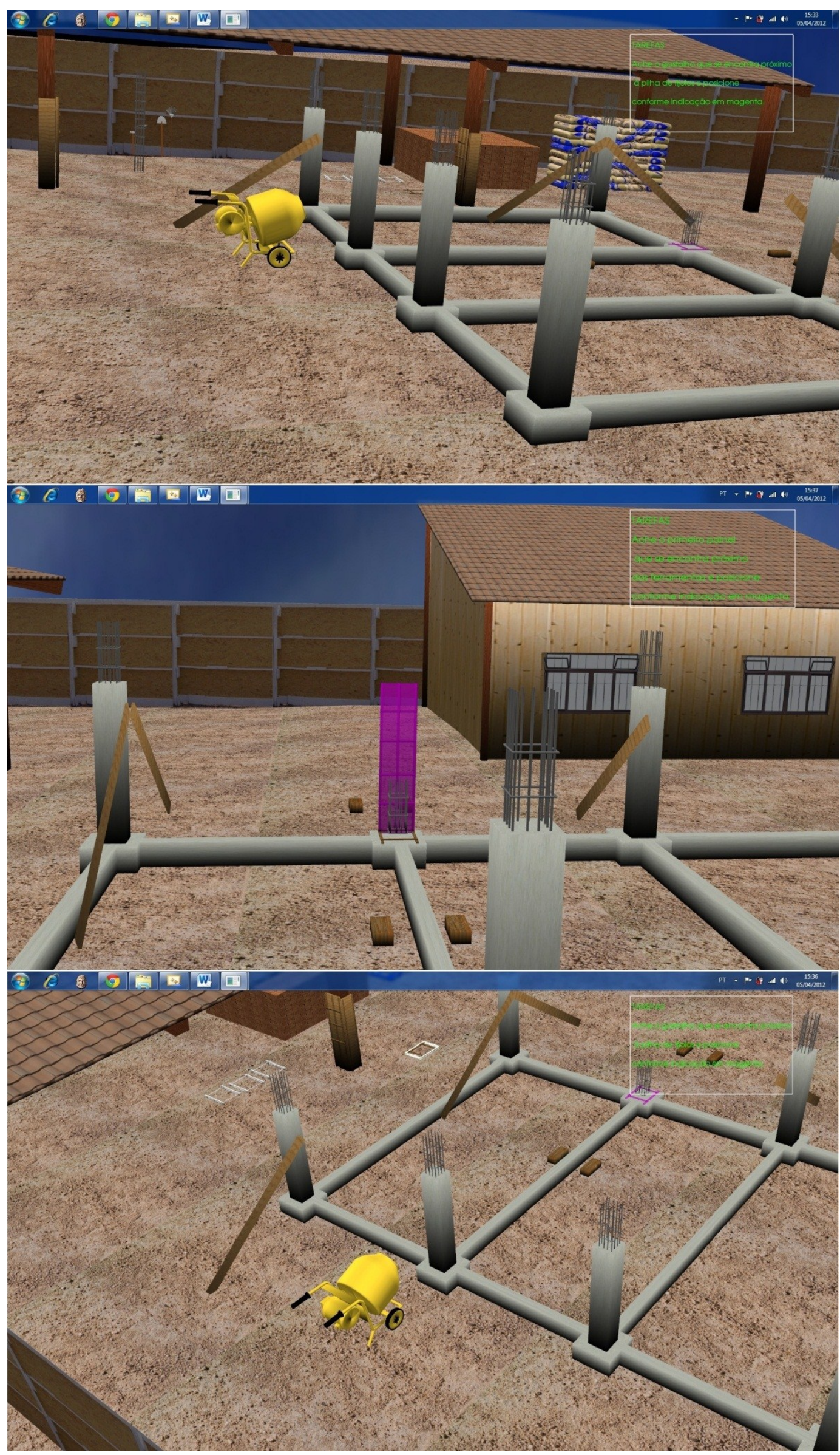

Figura 5. Cenas do ambiente protótipo. 


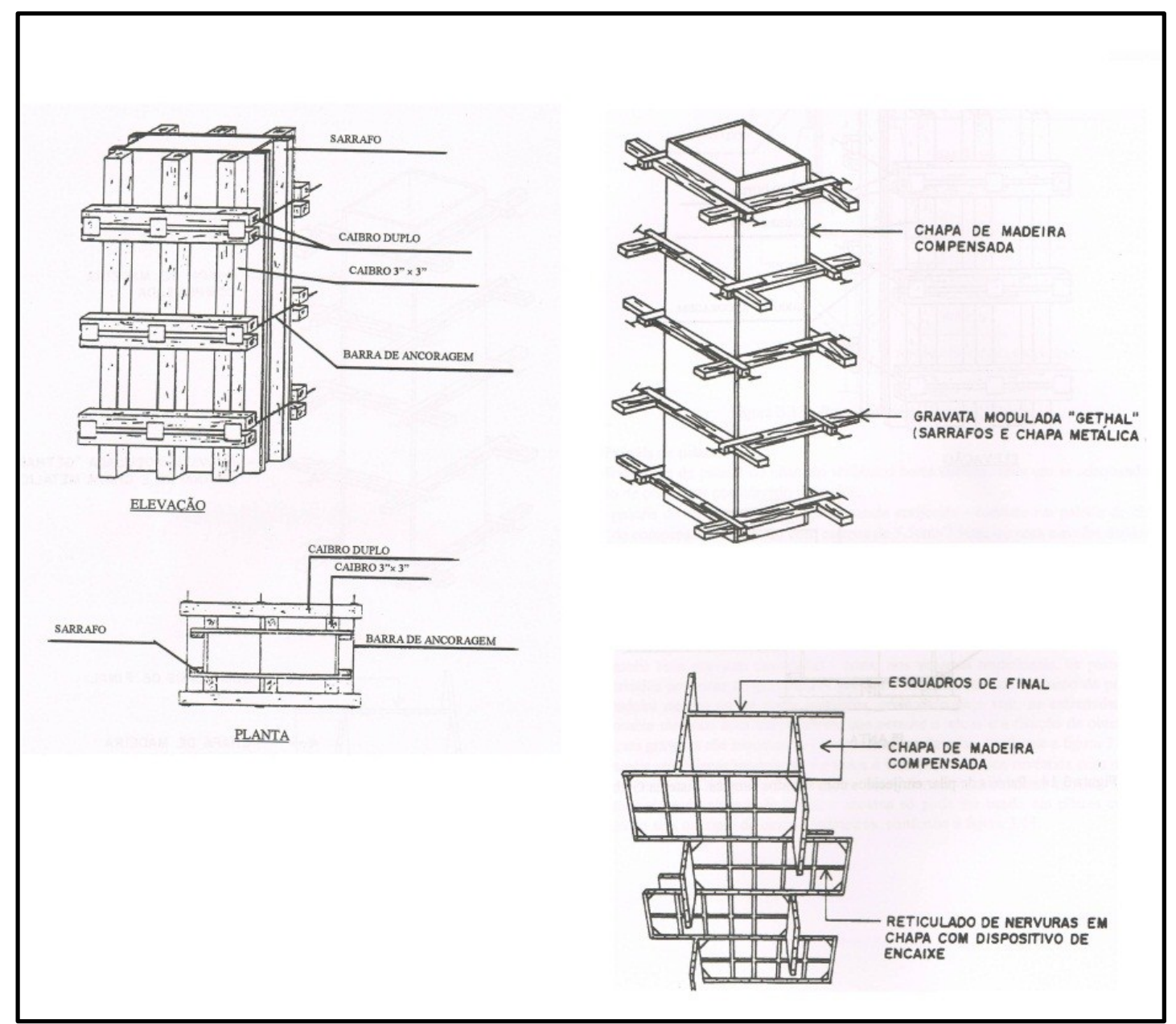

Figura 6. Modelos GETHAL para fôrma de pilar (ver [16]).

\subsection{Classes usadas do VTK: implementando o ambiente protótipo virtual}

$\mathrm{O}$ ambiente protótipo utiliza as classe do VTK e a linguagem de programação $\mathrm{C}++$ para importar a geometria e as texturas através dos formatos OBJ e JPEG respectivamente. Apesar de o VTK suportar o formato VRML (Virtual Reality Modeling Language é um formato típico usado em RV) através da classe vtkVRMLImporter, não há suporte para todos os nodes do VRML, especialmente o node ImageTexture responsável pela aplicação da textura. O VTK oferece ainda a classe vtk3DSImporter que herda os métodos da classe vtkImporter para gerenciar importação de arquivos em formatos típicos do 3DS Max (geometria e material). Mas como é uma instância da classe vtkRender ele direciona o dataset direto para renderer e dificulta o uso das classes para gerenciar e sincronizar a interatividade.

Para representar os objetos gráficos da cena foi usado o formato OBJ, comum aos aplicativos de modelagem gráfica 3D. A classe vtkOBJReader permite importar objetos geométricos no formato OBJ porém não foi achado uma classe ou método para importar material usando neste formato. Esta classe é um source object cuja saída é um polygonal data e quando mapeado através do vtkPolyDataMapper transforma os dados em primitivas 
gráficas. Cabe a classe vtkActor representar as primitivas gráficas na cena renderizada [17], [28], [29], [30].

As texturas são representadas por imagens no formato JPEG e importadas através da classe vtkJPEGReader que é um source object. O mapeamento das coordenadas da imagem para o modelo geométrico são feitas através da classe vtkTexture. Agumas propriedades da textura podem ser ajustadas usando: SetInterpolateOn( ) para interpolação da textura durante o render, EdgeClampOn( ) para adaptação da imagem quando ultrapassa o intervalo paramétrico [0,1], SetQualityTo32Bit( ) para a qualidade da textura. Atualmente o VTK suporta apenas texturas 2D. As instâncias do vtkTexture estão associadas com os atores através do método SetTexture( ) [17], [28], [29], [30].

Uso da classe vtkCamera possui métodos para manipular a câmera virtual. Os métodos SetPosition( ), Azimuth ( ), Roll( ) permitem o controle da posição e orientação da projeção da câmera. Uma vez que a câmera virtual está especificada ela pode ser usada pelo vtkRenderer através do método SetActiveCamera ( ) que recebe como argumento um vtkCamera. A navegação pela cena ocorre pela translação, rotação e controle do zoom da câmera virtual, que calcula as superfícies visíveis e a oclusão dos objetos [17], [28], [29], [30].

As luzes são ativas na cena através da classe vtkLight que simula um luz virtual durante o rendering. A classe possui métodos para posicionar, alterar cor, brilho. Pode simular tipos como spot light (cone de luz ou fontes de luz pontuais) e directional light (luz cuja posição está no infinito e os raios são paralelos, simulando fontes de luz como sol) sendo um tipo default [17], [28], [29], [30].

Objetos gráficos virtuais que necessitam de interatividade (peças da fôrma) para serem posicionadas na cena durante o treinamento usam as classes do 3 DWidget. Estas classes são subclasses de vtkInteractor, uma classe abstrata responsável por observar os eventos invocados na janela da classe vtkRenderWindow. Os widgets possuem representação própria na cena renderizada e oferecem diversos tipos de interatividades ao respectivo ator da cena, sincronizados através do método SetProp3D( ). Cada widget deve usar o método SetInteractor( ) para especificar o renderer ao qual se deseja adicionar o widget [17], [28], [29], [30].

No ambiente protótipo foi criado uma classe que herda vtkBoxWidget chamada vtkBoxWidget 1 como forma de manipular as peças para montar a fôrma do pilar de concreto. Algumas caraterísticas: não são visíveis na cena para não atrapalhar a identificação das peças através; não são visíveis e não estão ativados os handles e os outlinecursores que alteram escala e rotações indesejáveis; a classe já inicializa a posição do widget na cena. O quadro 1 apresenta a classe escrita em $\mathrm{C}++$.

A movimentação das peças (translação e rotação) acontece através da interatividade provida por vtkInteractor e vtkCommand, além de 3Dwidgets. Um vtkObject pode observar um evento qualquer através de uma das suas instâncias. Quando observa um evento ao qual está relacionado invoca um comando associado. Vale lembrar que o vtkCommand possui um ponteiro que se encontra nulo na maior parte do tempo do processo de visualização e quando ocorre um evento ela passa o vtkObject invocando o evento e não o evento em si.

O vtkInteractor ao contrário dos $3 D$ Widgets, não possui representação gráfica. Esta classe é a base para o suporte de eventos de controle de atores e câmeras virtuais numa cena, possuindo a maioria das rotinas de controle, tais como interatividade com mouse, joystick, 
trackball. Neste trabalho optou-se pelo uso de vtkInteractorStyleTrackBallCamera pois é uma classe que provê interatividade para se visualizar uma determinada área da cena de vários pontos de vista, auxiliando o usuário na visualização durante a manipulação de uma peça da fôrma.

A classe criada para interatividade no ambiente protótipo chama-se vtkMyCallback e herda a classe vtkCommand. Possui ponteiros para os atores e widget que representam as peças da fôrma; para os atores que indicam onde a peça deve estar posicionada na cena, chamados de ator indicador; e para a legenda, atualizando as informações. Quando uma peça está sendo selecionada ocorre uma comparação entre o widget da cena com o ponteiro da sequência de montagem. Se a comparação resulta em verdadeiro a interatividade é iniciada e a movimentação da peça acontece. Caso retorne falso não existe interatividade com a peça. As coordenadas são salvas por um array conforme a matriz linear de transformação do widget selecionado. Ao posicionar a peça próximo do ator indicador, o ajuste da posição final ocorre automaticamente através de uma transformação. A interatividade é encerrada e um novo indicador aprece na cena e assim é liberada uma nova interatividade para a próxima peça da sequência de montagem. O quadro 2 descreve o gabarito da classe vtkMyCallback escrito em $\mathrm{C}++$.

A legenda, através do vtkLegendBoxActor fornece as informações sobre quais peças devem ser selecionadas e posicionadas conforme o ator indicador. As informações são atualizadas conforme o usuário vai posicionando as peças, através do ponteiro da classe vtkMyCallback [27], [28].

\section{CONCLUSÃO}

Neste artigo foi apresentado conceitos sobre a Realidade Virtual e a atuação no processo de aprendizagem dentro do contexto educacional de arquitetura, engenharia e construção. Ainda foi proposto e desenvolvido um ambiente de treinamento técnico na construção civil que pode servir tanto para auxilio em sala de aula para os alunos compreender a tarefa simulada como também pode ser visto como um gabarito para implementações de outras técnicas e atividades voltadas à construção civil. Porém necessita de testes com alunos de engenharia civil e arquitetura para validar seu potencial no uso de aprendizagem e currículo das universidades. 
Quadro 1. Classe vtkBoxWidget1.

Quadro 2. Parte da classe vtkMyCallback.

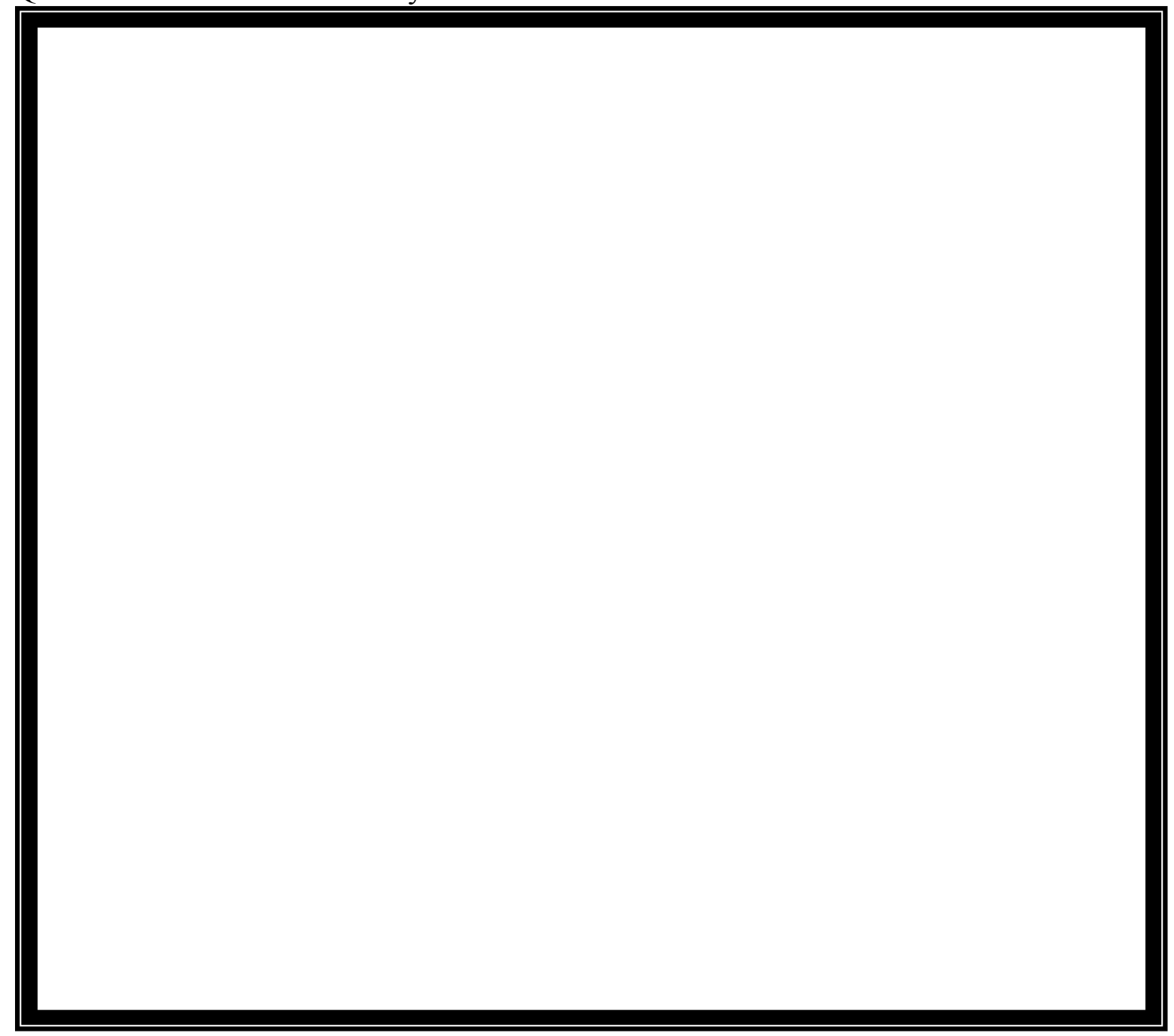




\section{Agradecimentos}

Os autores agradecem ao apoio financeiro da CAPE. Também agradecem a Alias/Wavefront, Silicon Graphics, Kitware Inc., Microsoft, GETHAL.

\section{REFERENCES}

[1] Adaime L. M., “Aplicação do Visualization Toolkit para pós-processamento de análises pelo método dos elementos". Dissertação (Mestrado em Métodos Numéricos em Engenharia) Universidade Federal do Paraná, 2005.

[2] Azevedo E., Conci A., “Computação Gráfica: teoria e prática.” Elsevier, 2003.

[3] Blanchard C., Burgess S., Harvil Y., Lanier J., Lasko A., Oberman M., Teitel M., "Reality built for two: a virtual reality tool." ACM SIGGRAPH' '90, 35-36, 1990.

[4] Bowman D., "Interaction Techniques for Common Tasks in Immersive Virtual Environments." Tese, Georgia Institute of Technology, 1999.

[5] Brodlie K. et al., "Scientific Visualization, techniques and applications". Springer-Verlag, 1992.

[6] Brodlie K., "A classification scheme for scientific visualization.” Animation and Scientific Visualization: tools \& applications. Academic Press, 125-140, 1993.

[7] Buriol T. M., "Processamento e Visualização de Campos em Ambientes Virtuais e Sistemas CAD 3D Aplicados a Projetos de Iluminação em Subestações". Dissertação (Mestrado em Métodos Numéricos em Engenharia) Universidade Federal do Paraná, 2006.

[8] Carvalho R. G., "Mudanças promovidas pela aprendizagem colaborativa e tecnologia da informação em sala de aula na disciplina Sistemas Estruturais." Dissertação (Mestrado em Construção Civil) Universidade Federal do Paraná, 2002.

[9] Cruz-Neira C., Sandin D.J., DeFanti T.A., "Surround-screen projection-based virtual reality: the design and implementation of the CAVE." " Computer Graphics, SIGGRAPH Annual Conference Proceedings, 1993.

[10]DeFanti T.A., Foster I., Papka M.E., Stevens R., Kuhfuss T., "Overview of the I-way wide area visual supercomputing.", Int. J. Supercomputer Application. 10, 123-130, 1996.

[11]Fisher S., "Recent developments in virtual experience design and production." SPIE 2409, 296. 1995.

[12]Foley J. D., Dam A. V., Feiner S. K., Hughes J. F., "Computer Graphic: principles and practice." $2^{a}$ ed. Addison-Wesley Publishing Company Inc., 1996. 
[13]Hutchinson T., Kuester F., Kim S., Lu R., "Developing an Advanced IT-Based Visualization Classroom for Enhanced Eng. Learning." International Conference on Engineering Education, Spain, 2003.

[14] Jacobson L., "Realidade Virtual em casa”. Berkley, Rio de Janeiro, 1994.

[15]Junior C. C., Okimoto F., Stamato G. C., Pfister G, "SET 613 - Formas de madeira para concreto armado". Universidade de São Paulo, Escola de Engenharia de São Carlos, 2000 .

[16] Katheleen A. Flannery K. A., Krauchunas S., "Virtual cognition lab: a constructivist approach toward learning." 3rd workshop on virtual reality, RGS, 2000.

[17]Kitware, "The VTK user's guide: install, use and extend The Visualization Toolkit". 2004.

[18]Krueger M., Gilden D., "KnowWhere: an Audio/Spatial Interface for Blind People." Proc. International Conference on Auditory Display (ICAD 1997), 1997.

[19] Machado L. S., “A realidade virtual em aplicações científicas.” Dissertação (Mestrado em Computação Aplicada), Instituto Nacional de Pesquisas Espaciais, 1997.

[20] Mäntylä M., “An Introduction to Solid Modeling.” Computer Science Press, 1988.

[21] Mccormick B. H., DeFanti T. A., Brown, M. D., "Visualization in Scientific Computing. "Report of the NSF Advisory Panel on Graphics, Image Processing and Workstations, 1987.

[22] McLellan H., "Virtual realities." In D. Jonassen (Ed.) Handbook of research for educational communications and technology, 457-487, 1996.

[23] Netto A. V., Machado L. S., Oliveira M. C. F., "Realidade virtual - definições, dispositivos e aplicações." Disponível em: www.di.ufpb.br/liliane/publicacoes/reic2002.pdf, Acesso em: 24.out.2011.

[24] Oliveira M. C. F. de, Minghim R., "Uma introdução à Visualização Computacional." In: JORNADA DE ATUALIZAÇÃO EM INFORMÁTICA (JAI) 16, 85-131. 1997.

[25]Pasqualotti A., "Ambientes VRML para o ensino-aprendizagem de matemática: modelo conceitual e estuda de caso." Dissertação (Mestrado em Ciência da Computação) Universidade Federal do Rio Grande do Sul, 2000.

[26]Pompeu R. C., "Um estudo sobre ambientes virtuais de apoio ao ensino e aprendizagem de resistência dos materiais." Dissertação (Mestrado em Métodos Numéricos em Engenharia) Universidade Federal do Paraná, 1999. 
[27] Seabra R. D., Santos E. T., "Utilização de técnicas de realidade virtual no projeto de uma ferramenta $3 \mathrm{~d}$ para desenvolvimento da habilidade de visualização espacial." Revista Educação Gráfica, 111-122, 2005.

[28] Schroeder W. J., Avila L. S., Hoffman, W., "Visualizing with VTK: a tutorial". IEEE Computer Graphics and Applications. IEEE, 2000.

[29] Schroeder W., Martin K., Lorensen B.," The Visualization Toolkit: an object-oriented approach to 3D graphics". 3rd. ed. Kitware, Inc., 2004.

[30] Van Dam A., Laidlaw D. H., Simpson R. M., "Experiments in immersive virtual reality for scientific visualization.” Computer \& Graphics 26, 535-555, 2002.

[31] Velho L., Gomes J., “Sistemas gráficos 3D.” São Paulo: IMPA, 2001.

[32] Yazig W., "A técnica de edificar - revisada e atualizada." 6ªed. Editora Pini, 2006.

[33]Zimmerman T.G., Lanier J., Blanchard C., Bryson S., Harvil Y., "A hand gesture interface device." CHI '87 Proceedings of the SIGCHI/GI conference on Human factors in computing systems and graphics interface., 1987 